Marquette University

e-Publications@Marquette

College of Education Faculty Research and

Publications

Education, College of

$7-1-2008$

Gender Observations and Study Abroad: How Students Reconcile Cross-Cultural Differences Related to Gender

Jody Jessup-Anger

Marquette University, jody.jessup-anger@marquette.edu

Published version. Journal of College Student Development, Vol. 49, No. 4 (July 2008): 360-373. DOI.

(C) 2008 American College Personnel Association (ACPA). Used with permission. 


\title{
Gender Observations and Study Abroad: How Students Reconcile Cross-Cultural Differences Related to Gender
}

\author{
Jody E. Jessup-Anger
}

Increasingly, global understanding is part of the core mission of institutions of higher education (Bollag, 2004). The National Association for State Universities and LandGrant Colleges (NASULGC Taskforce on International Education, 2004) issued $A$ Call to Leadership, urging university presidents to focus on internationalization as a way to enhance, broaden, and enliven academic learning, discovery, and engagement. Many colleges and universities recognize the need for globally literate citizens to meet the demands of an increasingly interdependent world and see study abroad as a way to develop students' cross-cultural skills (Bollag).

Paralleling administrators' acknowledgment of the importance of educating students for an increasingly interconnected world is students' increasing desire for international experiences. When students choose to study abroad, many do so to gain cross-cultural understanding and language proficiency or to satisfy a desire to travel and to have fun (Carlson, Burn, Useem, \& Yachimowicz, 1990). At their best, study abroad programs promote cross-cultural understanding so that students can become citizens of the world (NASULGC Taskforce on International Education, 2004). Ideally, as students become global citizens, they gain exposure to a variety of diverse cultures, fostering an appreciation for and comfort with multiple perspectives (Nussbaum, 1997). Although there is some evidence that students develop cross-cultural understanding through study abroad (Carlson \& Widaman, 1988; Kitsantas \& Meyers, 2001, Rea, 2003), many programs continue to provide students with limited tools for crosscultural interpretation, assuming that the immersion experience alone will be sufficient for students to learn about other cultures. This approach fails to acknowledge that students bring their own socially constructed identities and cultural assumptions to a host country (Twombly, 1995). These identities and assumptions influence and in some cases may distort the ways in which students approach, endure, and reflect on their experiences.

Oftentimes undergraduate students' study abroad experiences coincide with identity formation in late adolescence (Davis, 2002; Erikson, 1968; Jones, 1997; Jones \& McEwen, 2000; Josselson, 1987, 1996; McEwen, 1996). Not only does study abroad serve to enhance students' understanding of other cultures, it may be influential to the formation of self. Understanding how study abroad participants interpret their cross-cultural experiences can provide valuable information to anyone interested in fostering the development of students' identities and their understanding of difference.

Although there are many important areas in which to conduct research regarding how students' cultural assumptions and identities inform their cross-cultural understanding, for the purpose of this study the focus is on examining assumptions related to gender.

$\overline{\text { Jody E. Jessup-Anger is a doctoral student and research assistant in the Higher, Adult, and Lifelong Education Program }}$ at Michigan State University 
Gender is the social assignment of masculine and feminine characteristics to one's biological sex, in a cultural context (Grewal \& Kaplan, 2002). When students study abroad, many do so having an understanding of gender only from their home culture. Consequently, it is difficult for students to grasp the notion of gender as socially assigned because their gender assumptions often have been unchallenged since birth (Grewal \& Kaplan). Students' sometimes narrow and tacit definition of gender limits the way in which they see the world. However, when in a different country, most things feel new and different, so there may be less resistance to examining the subtle or distinct differences in the way gender is assigned and defined (Grewal \& Kaplan).

The purpose of the current study was to gain a better understanding of how gender was observed by a group of students participating in a 3-week study abroad program entitled, Food, Environment and Social Systems, which took place in Australia and New Zealand in May 2006. I examined the messages students received about gender in Australia and New Zealand, whether the students were cognizant of these messages, and how they made meaning of the messages in light of their own gender identity.

\section{REVIEW OF THE LITERATURE}

Two areas of literature inform the current study. The first explores identity development as a fluid process, influenced by contextual and sociocultural factors. The second examines emerging research on the influence of gender on study abroad.

\section{Identity Development}

Research about identity development has evolved to encompass more diversity than the early formulations by such scholars as Erikson (1968), which was predicated on samples of
White, middle-class men and assumed similarities in life experience (Jones, 1997). Jones and McEwen's (2000) conceptual model of multiple dimensions of identity is helpful in framing how a study abroad experience might influence gender identity development.

Drawing from their earlier individual work, Jones and McEwen's (2000) model reflects the diverse experiences, backgrounds, and contexts through which identity is formed. The model includes a central core, which serves to integrate the central identities of the student, including personal attributes and characteristics. Surrounding the core are rings of externally defined dimensions of identity, including gender, race, sexual orientation, socioeconomic class, and other identities (Jones \& McEwen). The proximity of each dimension of identity to the core identity is dependent upon the importance, or salience, of the particular dimension at a given time. The core and identity dimensions are set in a larger circle representing the context of a student's life, including "family background, sociocultural conditions, current life experiences, and career decisions and life planning" (Jones \& McEwen, p. 410).

Jones and McEwen's (2000) model is helpful in illustrating how a study abroad experience might influence the formation of gender identity. It has the potential to temporarily alter the context of a student's life. Living and learning in a different country and culture may unlock identity assumptions with which students were raised, encouraging them to be more aware of their externally defined dimensions of identity as they begin to explore and make meaning of alternative understandings in a new cultural context.

\section{Gender Identity and Study Abroad}

The literature on the intersection of gender identity and study abroad is emerging but still limited to a few qualitative studies in specific 
regions of the world. Twombly (1995) examined how gender identity influenced students' experiences with study abroad in Costa Rica. She found that for women in particular, "the first four months of the sojourn in a foreign country were not an immersion experience, but an alienating experience in which gender played a major role" (Twombly, p. 2). Twombly discovered that women students' difficulty making friends with members of the host country, coupled with their perceptions of harassment by men in the host culture, caused them to experience distress throughout their study abroad experience. Twombly's work was foundational, as it suggests that women students may have a difficult time negotiating their gendered identities in the context of a new culture during a study abroad experience. However, because no men were included in her study, there were no conclusions drawn regarding how men's socio-cultural assumptions, or those assumptions held between "the individual and his or her cultural context" (Schachter, 2005, p. 375), influenced their cross-cultural understanding.

Talburt and Stewart (1999) expanded upon the foundation built by Twombly (1995) through conducting an ethnographic study of students' experiences during a 5-week study abroad program in Spain. The authors found that, despite students' immersion into Spanish culture, they sought to understand the host culture by using their perceptions of life in the United States as a centering point. As a result, students' socio-cultural differences, including their differences in race and gender, often influenced how they made sense of their experiences within the host culture.

The work of Twombly (1995) and Talburt and Stewart (1999) illustrates how gender influences the way in which students experience another culture. However, neither study examined U.S. students' experiences in an Anglophilic country, where host culture language and customs might appear more similar to students' home culture than different. Nor did the existing studies make a direct connection to identity development. The current study set out to explore these gaps in the literature.

\section{RESEARCH DESIGN}

A constructivist epistemology guided the research study (Broido \& Manning, 2002). A qualitative case study approach, framed by a theory of feminist positionality, focused the data collection and analysis procedures. Feminist positionality theory (Alcoff, 1988) acknowledges that social identities (such as gender, race, sexual orientation, etc.) exist within a constantly changing context; however, it posits that from a particular context meaning can be constructed. Thus, "the concept of woman as positionality shows how women use their positional perspective as a place from which values are interpreted and constructed rather than as a locus of an already determined set of values" (Alcoff, p. 434). This theoretical framework enabled exploration of the possibility that male and female students might have different observations of gender and meaning-making mechanisms in Australia and New Zealand without insisting that all students would have the same observations and experiences in accordance with their gender.

Instead of examining how students experienced and made meaning of interactions with a different culture as a whole, I strove to examine how their observation and meaningmaking structures illustrated and informed their understanding of their own gender identity and the gender identities of those with whom they interacted in Australia and New Zealand. The case study approach is consistent with feminist positionality theory, as it encourages the researcher to choose a setting and then hone in on a particular aspect of it (Creswell, 2007). 


\section{Procedure}

Participants. Participants in the study were 9 of the 28 students ( 19 women, 9 men) on the study tour. Five female students and four male students completed the study. Participants ranged in age from 20 to 24 years old. All but two students identified as White or Caucasian, with one student identifying as LebaneseAmerican and another opting not to selfidentify. Seven participants were pursuing majors within the College of Agriculture and Natural Resources, and two were pursuing degrees in areas unrelated to the academic focus of the trip. None of the participants had been to Australia and New Zealand before, although five of the participants had been abroad before. All of the participants paid for part of the trip themselves or with the help of parents, with one participant receiving no financial support from parents. Two participants had the costs of the trip partially defrayed by merit-based scholarships. All of the participants classified their socioeconomic background as middle class or upper-middle class. The participants in the study were representative of the overall group.

Purposive sampling (Patton, 1990) was used to select students for participation in the study. Using public biographies from the study tour website and my observations of students' participation during orientation, I created a list of students who were diverse in terms of majors, life experiences, and interests and who I believed would provide information-rich descriptions of their experiences and observations. During the first week of the trip, I began selecting a mix of men and women from the list and asking if they would be interested in participating in the study. All the students I asked agreed to participate with the exception of one student, whose post-trip commitments limited her availability for a follow-up interview. One other student initially agreed to participate, but took a job in another state upon return to the United States, making the follow-up interview impossible to conduct. I stopped soliciting participants to be interviewed when I believed that maximum variation had been reached in terms of students' responses, majors, and the social groups into which they had self-selected on the trip (Patton, 1990). The participants chose or were assigned the following pseudonyms to protect their confidentiality: Amber, Danielle, Elizabeth, John, Kevin, Michael, Ruby, Sandra, and Tony. I changed one pseudonym after discovering that it was a nickname used to identify the participant while on the trip.

Setting. The setting of the study was a 3-week study tour entitled, Food, Environment and Social Systems, sponsored by the College of Agriculture and Natural Resources and the College of Social Science at Large Midwestern Research University (LMRU), a large research extensive university located in the Midwest. Prior to the study tour, the students participated in seven 2-hour orientation sessions led by the faculty facilitators. These sessions provided the opportunity for students to get to know one another, to ask questions about the trip, to gain a better understanding of the sites and cities to be visited on the trip, and to discuss appropriate behavior on the trip. General information about the culture was provided to students, including different words they might hear in the host countries, different food they might encounter, and a historical overview of each country's political structure.

The tour commenced on the South Island of New Zealand where we spent a week touring the countryside via bus, visiting different cities and attractions. Typically tour guides, content experts (park rangers, farmers, etc.), or university administrators met the group and provided information regarding the region or attraction. In addition, faculty facilitators from LMRU conducted two reflection sessions while 
in New Zealand, asking students questions about their observations and experiences. Students also had one "free day" in Queenstown, NZ, where they could choose how to spend their time. While in New Zealand we stayed in hotels, with the exception of one evening, during which we stayed on a farm with a family in groups of between two and six. Many students drew from their experiences with the farm stay to observe and make meaning of the culture in New Zealand.

The study tour continued on to the east coast of Australia, where we spent 2 weeks touring the eastern coast via bus, train, and plane. Instructional methods were similar to those in New Zealand. While in Australia, the faculty facilitators conducted two additional reflection sessions. There were two free days in Australia. We stayed mostly in hostels while in Australia, with the exception of Sydney, where we stayed in a hotel.

A tenured faculty member and an administrator from LMRU planned and led the trip. Most of the content of the trip would be considered gender-neutral, with presenters communicating information in a way that neither highlighted nor placed more value on one sex over another. However, there were times when I noted the lack of a female presence and tacit assumptions of prescribed gender roles, including during a young farmers panel, where solely male farmers shared their experiences with farming in New Zealand, and at the U.S. Embassy, when the U.S. official greeting us opened his comments with a sexist joke.

Most of the interactions between students and the local citizens occurred in the capacity of service, including interactions in restaurants and stores, and interactions with tour guides and speakers. Students also interacted with local citizens during their free time, typically while out at bars in the evening and during their free days. Finally, students interacted with locals during their farm stay in New Zealand.

Method. Several methods were employed in investigating the research questions. First, I engaged as a participant-observer in all the formal and some informal experiences encountered by the students, taking copious field notes of my observations. I resided among the students in the hotels and hostels and on the farm stay. In addition, I ate most of my meals with students and, on occasion, accompanied students to evening activities, which typically meant going to a bar. I also spent two of the three free days with students.

Second, I conducted two sets of individual, semi-structured interviews with 9 of the 28 students, with the first set of interviews taking place during the second half of the trip and the second set about 6 weeks after the end of the trip. The first set of interview questions focused on the participants' observations of the cultures of Australia and New Zealand and their perceptions of the differences among and between the two cultures and the United States. The questions also examined students' feelings regarding the trip, including how they believed they were changing, what they perceived as stressful, and how the trip might be different if they were another gender. No mention was made to the students that I was exploring their observations specifically related to gender so as not to falsely influence their perceptions or responses. The only question that related to gender was embedded in the interview questions. The follow-up interview questions were more pointed, focusing again on participants' experiences and observations, but also inquiring about their observations of gender roles in the host cultures and their perceptions of race and ethnicity. Furthermore, questions were asked about participants' transition back to the United States and their observations since returning.

Finally, upon return to the United States I collected, read, and coded the reflection 
journals kept by students throughout the tour as part of their course requirements. The journals served primarily to reiterate some of the observations students discussed in their interviews and also provided additional context and insight regarding the various settings and interactions among students while on the trip.

Establishing Trustworthiness. Several steps were taken to ensure trustworthiness (Creswell, 2007), including transcribing interview data verbatim, corroborating participants' responses with notes taken during the interviews and while on the study tour, gathering data at different points in time and through different means, and discussing results of the data with several colleagues. In addition, after the second set of interviews, a synopsis of the interview was sent to each participant as a way to ensure that they believed they were being represented accurately.

Limitations. Although careful steps were taken to ensure the data collected reflected the experiences of the students on the program, several limitations are important to note. First, because a single case study approach was used, comparisons across different programs were impossible to make. In addition, although students were observed throughout the duration of the trip and interviewed at several points in time, their enduring meaningmaking structures beyond the first month after the completion of the trip remain unknown.

\section{Analysis}

Having spent significant time over the past several years acutely aware of gender dynamics in the collegiate environment, I observed gender dynamics constantly while on the trip, noticing the gender of the person who was speaking to us, whether the person's gender was overtly informing the content of the conversation, the tone of voice in which he/ she chose to speak, to whom the person addressed comments, and the assumptions he/ she made about gender roles in his/her comments. Discussing my observations with a trusted colleague assisted me in bringing forth some of my judgments about what students might have noticed and experienced with regard to gender in the host country. Only after recognizing my own judgments was I able to identify what the students did and did not observe and experience.

Data analysis was initiated by thoroughly reading the transcripts, coding based upon emergent themes related to gendered observations, and scanning for patterns among and between the participants (Creswell, 2007). I used the journals kept by the students to discern additional observations they made about gender and also to ascertain how they were making meaning of their experiences.

\section{FINDINGS}

Comparative discussion about gender and other aspects of identity was largely absent in the formal instruction of the study abroad program. Consequently, students were on their own to observe and discern differences and similarities about their own culture and the cultures of the host countries. Through observations of students during the study abroad program and the interviews conducted during and after the program, the following themes arose. First, generally students did not pay attention to gender roles in the host cultures. Second, several students witnessed or experienced harassment or sexism they attributed to gender, despite not paying attention to gender dynamics. Third, although they were not mindful of gender in the host cultures and downplayed harassment when they experienced or witnessed it, all the students possessed embedded assumptions about what it means to be male and female in the capacity of study abroad, through which they made judgments of their peers. 
Generally Participants Did Not Pay Attention to Gender Roles in the Host Cultures

During both sets of interviews, students made few unsolicited observations about gender in the host cultures. When asked to describe the cultures of Australia and New Zealand during the first set of interviews, only Amber used gender as part of her analysis. The other students described their observations of the culture as being laid back, friendly, and less materialistic.

In addition to most students not mentioning gender in their initial interviews, the daily reflections of students' journals only revealed scant references to gender, with Tony, Kevin, Danielle and Elizabeth mentioning nothing about gender, John and Michael mentioning gender once, Ruby and Sandra mentioning it twice, and Amber mentioning it four times. Typically, when students mentioned a gendered awareness, such as Sandra writing about the display of masculinity in the Maori cultural concert or Ruby discussing her observation of women in Australia being more fashion conscious, they reported their observation at face value. When students did attempt to make deeper meaning of their observations, they used gendered assumptions to guide their analysis. For example, Michael wrote that there were more female teachers than male teachers in the primary school in Australia. He noted that the ratio was similar in the United States and concluded that it might be due to the psychological connection between a mother and child that causes females to go into teaching more than males. Amber also mentioned the ratio of female to male teachers and speculated that it might be greater due to the fact that the school was located in the capital city, and consequently more men were involved with the government instead of teaching.

In the follow-up interviews conducted 6 weeks after the trip, students were asked directly what they observed about gender in the countries we visited. All of the students, with the exception of Michael and Amber disclosed that they paid little attention to gender while on the tour. Tony and John used the farm stay as an example to illustrate that gender roles were more rigid in New Zealand, but both also noted that they were not purposeful in observing gender. Danielle also divulged that she generally didn't pay attention to gender, but illustrated her belief that more chivalry exists in Australia and New Zealand by sharing an observation she made in the bathrooms of both countries that the trash cans are designed to be more sanitary. It was interesting to me that she determined that the difference was about chivalry and not about a value of cleanliness.

Ruby, Kevin, and Elizabeth shared that they did not see any differences in gender roles of people in Australia and New Zealand and people in the United States. Elizabeth explained that she did not see a stereotypical role for women in New Zealand, just like she doesn't see one in the United States. Ruby thought that she might make additional observations were she more immersed in the cultures, doing something like searching for a job.

Michael and Amber were the only two students who shared substantive observations when asked about gender roles in Australia and New Zealand. Michael related gender to marriage and shared how he was intrigued with the notion that not all people in Australia choose to marry, a fact he heard explained by one of the tour guides. He explained:

I just like how they don't have marriage. How they have marriage but they don't call it marriage. They are partners. I mean, if I could live here, that's how I'd want to do it, because marriage seems to scare a lot of people. Like the word, "marriage," or spending the rest of your lives together, 
it just seems like having a partner, you're more just like, yeah, you're committed or whatever, but it's like an understanding, it's not a legal document binding us, it's mental, it's emotional. So, I think it's a lot more powerful than it is for saying our names are on a piece of paper that means we're together, which is cool because that's our culture. I don't know if that's how they [all] do it over there, but it just seemed cool, the fact of having this person I love, and that's how it is, you know, I don't need a piece of paper. I kind of like that aspect.

Later in his interview, Michael explained that he viewed the idea of marriage as constraining. He equated it to becoming a provider, which he believed would mean he would no longer be able to lead an adventurous life. Amber's observations of gender in New Zealand also dealt with marriage. She recounted her observation regarding the roles of men and women on her farm stay both in her initial interview and also in the follow-up interview. Her statements revealed embedded assumptions about gender roles and also a desire to change the way she believes gender is constructed in the United States. Amber explained,

In New Zealand, typically the wife seemed like she stayed home, which makes sense because they are farmers and like every other place, typically the farming community, the males are the biggest part of it. But yet again, even though she was a stayat-home mom or wife, a lot of [the wives] contributed to the income. And, the women actually did go outside and help the husband. ... So in a way [the wives] are like stay-at-home moms, in that they are not as inclined to go get a job the way that my mom would if my dad were a farmer. [Women getting a job] seems more typical in the U.S. [where] the woman is much more independent, probably because of our high divorce rate and our need to be good and rich. Not many women work outside the home in New Zealand, and I think it it's because in the farming communities, they just didn't seem as interested in rank and money as we are in the US. . . I like the thought of being at home but still bringing in income somehow. The women take on almost the same role as the men do, or part of their time is spent doing what the men do, and part of their time is either just being a mom, or bringing in income through bringing visitors into their home. Women in the US get a really bad rap for being a stay-at-home mom.

In talking with both Michael and Amber, I got the sense that their observations of gender were somewhat self-serving, in that each seemed to be looking for an alternative model that was more in line with their values. So, although generally students did not take notice of gender dynamics in the host culture, they may have noticed more when the dynamics provided an alternative to their gender socialization that was more in line with their values.

\section{Students Described or Witnessed Sexism or Harassment but Underplayed the Significance}

Although participants did not make many observations about gender, three students, John, Sandra, and Elizabeth, encountered or witnessed situations in which they believed that gender played a part in how they or others were treated. Elizabeth recounted an experience she had on her farm stay where she felt like she was treated differently because she is female. She explained:

I think that on the farm stay, the guy we stayed with, he was more traditional, not like male dominance but more like more superior. It seemed like he targeted the males in my group when he was talking. ... We did a dairy visit and I come from a dairy background and I had many 
questions, but it seemed like I had to push my way up there to ask them because he was targeting [the males] and it seemed like he thought that they would know more and appreciate it more. But from the group I was the one that had the questions - that had the desire to be there.

Interestingly, Elizabeth later explained that she did not feel like she experienced discrimination, nor did she witness any discrimination targeted toward females while in Australia and New Zealand. John, who stayed on the same farm as Elizabeth, also believed that the men on the farm stay were treated differently than the women. He stated:

I think you experience a different part of the culture, being a male versus female, especially on my farm stay in New Zealand. I think that the adult, the man, was much more receptive to talking to us, like me and [another male student], as men, than he was to the three other girls, regardless of what they had to say. So, I mean there was [sic] some chauvinist things there and I think we were allowed to break through and talk to him intelligently and he wasn't willing to do that with [the women], whether it had been their fault a little bit or mostly his fault.

In John's follow-up interview, he brought up his observation regarding the male host's treatment of men and women on the farm stay again, but this time he placed more blame for the interaction on the female students. John explained that from his perspective the women did not make an effort to talk to the male host. When questioned further, he conceded that the women might have been picking up on cues from the host, but stated that everything turned out all right because the female students went to bed anyway.

Sandra also recalled an experience at a pub in Sydney where one of her female friends was being harassed by an Australian. She explained:
[The Australian] drank too much and was making inappropriate gestures to one of my friends. And, I being more of the sober one of everybody felt like I had to protect her. And even when I did, he didn't do a thing. So obviously he is not going to do something unless a guy steps up. That was really the only time that I felt the differences between the sexes ... and it's not like it doesn't happen in the United States.

Although these students witnessed or experienced sexism and harassment they attributed to gender difference, they downplayed the significance of the experiences, with several of students excusing the behavior based upon behavior they had witnessed at home and others changing their recollection of the events as time went on.

\section{Students Possessed Embedded Assumptions About What It Means to Be Male and Female}

Although students generally did not pay attention to gender in the host culture, even excusing and downplaying sexism and harassment, they all possessed embedded assumptions about what it means to be male and female through which they interpreted their experiences. During the first set of interviews participants were asked to discuss how they believed their experiences on the trip would be different if they were another gender. All the participants stated that they believed the trip would be different. With the exception of Amber and Kevin, all the participants described assumptions that positioned males to have a better experience on the program. The reasons that the participants believed it was preferable to be male varied and revealed tacitly held assumptions about gender roles.

One belief that students held was that it was easier to be male on the trip because the conditions on the trip were more challenging 
for females. Tony explained:

I think males might have a tendency not to get as homesick as the girls, and I think they can deal with the long days better. ... I think girls get more attached to their parents, [they] call home a lot more than the guys. I think I have noticed that because I have only called home once actually, and I talked to the guys and they only called home a couple times.

Michael echoed Tony's statements, commenting:

I think a lot of the girls had a hard time with the food over here. I even heard comments like, "You know all the food over here is so weird and why don't they have normal food." . . . It just feels like some of the females are picky eaters and that's kind of caused problems, when most of the guys on the trip are like, you know, "Just put food in front of my face, let's eat it."

John too thought that being male made the trip easier, particularly the hostel stays. $\mathrm{He}$ explained:

I think there's a lot more that goes into getting ready for women. I think the guys are pretty adept to just kind of sleeping or hanging out with a bunch of guys in one room, one shower, it doesn't really matter. We pretty much get along with it. It doesn't really cause any tension or anything. I think with the girls, there's a lot more preparation that it takes to get ready in the morning, and I think that there's probably a little more time put there naturally than there is for the men.

Several women also believed that being male made the trip easier. When asked how the trip might be different if she were male, Ruby shared that she believed that being female limited the options for women, but considered herself an exception to the rule. She illustrated this point, explaining,
Well, maybe some of the difference may be [that] guys would be less scared to try new things or jump in the freezing cold water, like when we were on Doubtful Sound, only two girls did it and all the guys did. But it doesn't really bother me because I knew that I wanted to do all that stuff.

Danielle also revealed some assumptions about gender roles when she described how she believed the trip would be different if she were male. She stated,

It seems like maybe with girls, they tend to be a little bit more catty about things, so a lot of times guys have this more laid back attitude, so if I were a guy experiencing this, maybe I wouldn't be uncomfortable with the group as much.

Danielle also revealed assumptions about gender roles when she shared her feelings of intimidation regarding the male trip facilitators. She posited that if the faculty members were female, the trip might be a more relaxing or nurturing. When asked why she believed the trip would be different, she explained, "I guess it's kind of different because we are all these young girls with [the faculty] and there's some things that feel more male oriented." When asked what some of the things were, Danielle became uncomfortable and backed off her statement. The general sense from some of the students was that male students had an easier time adjusting to the discomfort of the study abroad program.

Another assumption shared by two of the male students was their belief that being men meant embracing the role of protector over the women on the trip. Not only was this assumption held, it was also acted upon, and reinforced by one of the faculty facilitators who asked the males to watch over the females before the students headed out to a bar. About embracing the role of protector, John stated: 
Being male I think that I try to shelter, I think I try to protect the women on the trip, especially at night when we go out ... which is definitely a major part of the study abroad, well, for some of the students. I think I feel more like I need to protect them.

Playing the role of protector was agreed upon by several male students. In his initial interview, Michael explained how he and John had discussed their roles:

Going out at night, me and John have both talked, [and] we've placed it upon ourselves with all the girls ... [to] make sure that one of us is with [them] at some point in time. You know we don't want anyone walking home by herself, and I think that that's one thing that's different between the males and females, like last night [another male student] had one too many and was going home by himself. I didn't worry about him because he's a guy. But if that would have been a girl going home by herself, I would have been like, "No way, wait for ... one of us, or let me walk you home."

Although most of the students held assumptions about gender that led them to believe males had an easier time adapting on the trip and that they should serve in the role of protector, two students shared their assumptions that being female was an advantage. Amber, who recounted the greatest number of observations related to gender in her journal and also in her interviews, held the assumption that being female caused her to notice gender in a way that her male counterparts would not. Kevin held the assumption that men and women had the same experience on the trip, with women gaining the advantage of having drinks bought for them. He justified this "advantage" by explaining that it happens in the United States too. He did not attempt to make meaning of his assumption that females had an advantage.
Students revealed assumptions about gender when they speculated how the trip might be different if they were another gender. These embedded assumptions about gender framed how they viewed and made sense of their experiences.

\section{DISCUSSION AND RECOMMENDATIONS}

The findings of the current study illustrate that in some cases a change in cultural context alone is not sufficient to make gender more salient, which according to Jones and McEwen (2000) is necessary to advance the formation of identity. Unlike the women in Twombly's (1995) study, whose experiences within the host culture were different enough from their own culture to cause them to feel significant distress and perhaps bring about new (and painful) identity awareness related to gender, women and men in the current study rarely took note of gender in the host cultures, and when they encountered or experienced harassment, they downplayed and excused the significance. The difference in reaction could be related to a whole host of factors, including not having a language barrier, more limited interactions with the host culture, a shorter amount of time spent abroad, and the students' life experiences leading up to the trip.

Consistent with Talburt and Stewart's (1999) findings, which demonstrated that students use their experiences in their home country as a centering point, the current study's findings revealed that, without a sharp contrast in home and host cultures, gender roles are not observed and are thought to be the same as in one's home culture. Elucidating these embedded assumptions is difficult, yet essential to greater understanding of other cultures. Lorber (2000) illustrated the difficulty in making gender visible for students, explaining, 
Gender is so much the routine ground of everyday activities that questioning its taken for granted assumptions and presuppositions is like wondering if the sun will come up. Gender is so pervasive in our society that we assume it is bred into our genes. Most people find it hard to believe that gender is constantly created and recreated out of human interaction, out of social life, and is the texture and order of that social life. (Lorber, p. 203)

Although the task of unraveling gender assumptions might be difficult, it is critical to cross-cultural understanding and gaining a deeper understanding of one's own identity. When assumptions remain unexamined, students may miss the "teachable moments" fostered by a new cultural context and instead apply gender stereotypes learned in their culture to other cultures. For example, when unexamined, U.S. students may assume that the role of a female head of state is an anomaly instead of examining more deeply how the political structure in the host country is more conducive to equal representation in government. In addition, they may view mandatory military participation of men as "the way the world works," instead of deconstructing the gendered assumptions about how it came to be that way. In not examining their own embedded assumptions, students risk developing a false understanding of a new culture, one that is laden with judgment informed through their own sociocultural context, as opposed to the context of the culture in which they are visiting.

Students also risk forging an uncritical and complacent attitude of their own culture by not exploring their embedded gender assumptions. The current study illustrates the consequences of this uncritical stance in students' reactions to observations of sexism and harassment. Because the harassment and sexism were not sufficiently traumatic to cause great duress to the students who witnessed and experienced it, they dismissed it as no big deal. Downplaying the impact of harassment and sexism is an effective coping mechanism to a point, as it allows students, and particularly women, to continue to function effectively in a society that oftentimes subtly regards them as less than men. However, by not responding to and reflecting on sexism and harassment, students run the risk of positioning themselves to accept increasingly objectionable conduct. Just as a gradually increasing problem with smog in the air we breathe might be unnoticeable but ultimately will affect our health, an apathetic response to sexism and harassment may only lead to a lack of acknowledgement and indifference to unacceptable behavior. Understanding how our cultural assumptions mediate our responses to these types of behaviors is important to developing a more informed understanding of ourselves. The new cultural context experienced during study abroad provides an opportunity for students to reflect on their home culture as well as the host culture. However, for many students, the cultural context alone is insufficient to bring about reflection; it must be coupled with a guided extraction and illumination of assumptions.

In light of the findings of the current study, I offer recommendations relevant to all student affairs administrators and also some specifically pertinent to those charged with developing and administering study abroad programs. First, all student affairs educators should acknowledge that students' embedded sociocultural assumptions influence the way that they make meaning of the world and provide opportunities for students to surface and understand these assumptions. Regardless of if students are preparing to study abroad, to enter the workforce, or to live successfully with a roommate, it is vital that they understand how the multiple dimensions of their identities interact to inform their understanding of themselves and others. The more 
opportunities students have to articulate who they are, how they see the world, and what informs how they understand and make meaning of their own culture, the more easily they will be able to identify and explore cultural differences. As globalization continues to shrink the distance between people, it is critical that students have the skills to communicate across difference, and they certainly do not need to go abroad to encounter cultural differences. Student affairs educators are in a unique position to assist students in fostering the holistic development of their identities through co-curricular experiences. Educators in functional areas as diverse as student leadership, career services, residence life, academic advising, and campus activities can assist students in surfacing the assumptions with which they have been raised so they can gain a more accurate picture of themselves as gendered beings.

Second, student affairs administrators should partner with faculty and others who take students abroad to ensure that the formal study abroad curriculum supports holistic student development (i.e., the tools that students need in order to observe and make meaning of the new cultural context). Regardless of the subject matter covered during a study abroad program, part of the power in the experience is the different cultural context in which it is conveyed. To omit discussion of the new cultural context within the formal curriculum is to allow the elephant in the room to block students' view of the chalkboard; learning will be disrupted and ultimately inadequate. For students to gain cross-cultural understanding, it is essential that they engage in cross-cultural comparison and reflection with peers and that they be given opportunities to explore and challenge the assumptions they bring to the experience. Student affairs educators possess important knowledge about how to create seamless learning environments that engage students in learning in all facets of their lives. Collaborative relationships between faculty and student affairs educators must be fostered to ensure that the unique blending of in-class and out-of-class experiences in study abroad is adequately captured to promote holistic learning.

Finally, and perhaps most importantly, as study abroad programs continue to shorten in length (Institute of International Education, 2004), study abroad coordinators must work with faculty and administrators leading programs to ensure regular opportunities are provided for students to interact in meaningful ways with members of the host culture. Many students in the current study drew their observations of the host culture from the experiences in which they had the most meaningful interaction with the culture, namely during their farm stays and while out at the bars. Several students in the current study commented that they had not interacted enough with the host culture to develop a meaningful understanding of the culture. By encouraging regular interaction with the host culture via home stays, organized meals with members of the host culture, and integrated classes with students from the host culture, students will understand the culture more deeply than they would if their primary interaction with the host culture is through tour guides and service providers including salespeople, waiters, and bartenders.

\section{CONCLUSION}

Study abroad experiences offer a unique opportunity for students to reconsider the assumptions with which they have framed their understanding of the world in which they live. However, as illustrated by the current study, the experience of study abroad alone is often insufficient in fostering the reflection and self awareness necessary to bring about such 
reconsideration. Although the current study examined students' sociocultural assumptions related to gender, the findings have implications for other sociocultural dimensions of identity, including race, sexual orientation, and socioeconomic status. Additional research should be conducted on these other identity dimensions to understand how students' assumptions influence the ways they understand a new culture in light of these assumptions.

As study abroad programs address the sociocultural assumptions students bring to a host culture, they will assist students in examining critically how gender and other

\section{REFERENCES}

Alcoff, L. (1988). Cultural feminism versus post-structuralism: The identity crisis in feminist theory. Signs. 13(3). 405-436.

Bollag, B. (2004, November 19). Get out of the country please. [Electronic version]. The Chronicle of Higher Education, A42.

Broido, E. M., \& Manning, K. (2002). Philosophical foundations and current theoretical perspectives in qualitative research. Journal of College Student Development, 43. 434-445.

Carlson, J. S., Burn, B. B., Useem, J. M., \& Yachimowicz, D. (1990) Study abroad: The experience of American undergraduates. New York: Greenwood Press.

Carlson, J. S., \& Widaman, K. F. (1988). The effects of study abroad during college on attitudes toward other cultures. International Journal of Intercultural Relations, 12, 1-17.

Creswell, J. W. (2007). Qualitative inquiry and research design: Choosing among five approaches (2nd ed.). Thousand Oaks, CA: Sage.

Davis, T. L. (2002). Voices of gender role conflict: The social construction of college men's identity. Journal of College Student Development, 43. 508-521

Erikson, E. H. (1968). Identity: Youth and crisis. New York: Norton.

Grewal, I., \& Kaplan, C. (2002). An introduction to women's studies: Gender in a transnational world. New York: McGraw-Hill.

Institute of International Education. (2004). Open doors: Report on international educational exchange. New York: Author.

Jones, S. R. (1997). Voices of identity and difference: A qualitative exploration of the multiple dimensions of identity development in women college students. Journal of College Student Development, 38. 376-385.

Jones, S. R., \& McEwen, M. K. (2000). A conceptual model of multiple dimensions of identity. Journal of College Student Development, 41. 405-414.

Josselson, R. (1987). Finding herself: Pathways to identity development in women. San Francisco: Jossey-Bass.

Josselson, R. (1996). Revising herself: The story of women's identity from college to midlife. New York: Oxford University Press. dimensions of identity complicate questions regarding who holds the power, access to money, and means to survival in a host culture. Only then will students be able to analyze current international issues, events, and opportunities with a lens that is sharpened to recognize cultural differences from a gendered perspective, allowing them to view their own and other cultures more critically.

Correspondence concerning this article should be addressed to Jody Jessup-Anger, $401 \mathrm{~F}$ Erickson Hall, Michigan State University, East Lansing MI 48823; jessupa1@msu.edu

Kitsantas, A., \& Meyers, J. (2001, March). Studying abroad: Does it enhance college student cross-cultural awareness? Paper presented at the combined Annual Meeting of the San Diego State University and the U.S. Department of Education Centers for International Business Education and Research, San Diego, CA.

Lorber, J. (2000). Night to his day: The social construction of gender. In M. Adams, W. J. Blumenfeld, R. Castaneda, H. W. Hackman, M. L. Peters, \& X. Zuniga, Readings for diversity and social justice (pp. 203-210). New York: Routledge Press.

McEwen, M. K. (1996). New perspectives on identity development. In S. R. Komives \& D. B. Woodard, Jr. (Eds.), Student services: A handbook for the profession (3rd ed., pp. 188-217). San Francisco: Jossey-Bass.

NASULGC Taskforce on International Education. (2004). A call to lead: The presidential role in internationalizing the university. Retrieved September 24, 2005, from http://www. nasulgc.org/NetCommunity/Document.Doc? $\mathrm{id}=32$.

Nussbaum, M. (1997). Cultivating humanity: A classic defense of reform in liberal education. Cambridge, MA: Harvard University Press.

Patton, M. Q. (1990). Qualitative evaluation and research methods (2nd ed.). Newbury Park, CA: Sage.

Rea, L. L. (2003) Responses and outcomes to international curricula offered off and on campus: Two case studies at Hiram College. International Education, 32(2), 40-62.

Schachter, E. P. (2005). Context and identity formation: A theoretical analysis and a case study. Journal of Adolescent Research, 20, 375-395.

Talburt, S., \& Stewart, M. A. (1999). What's the subject of study abroad? Race, gender and "living culture." Modern Language Journal, 83. 163-175.

Twombly, S. B. (1995). Piropos and friendships: Gender and culture clash in study abroad. Frontiers: The Interdisciplinary Journal of Study Abroad. 1, 1-27. 